Retraction

\title{
Retracted: Growth Responses and Leaf Antioxidant Metabolism of Grass Pea (Lathyrus sativus L.) Genotypes under Salinity Stress
}

\section{International Scholarly Research Notices}

Received 7 August 2016; Accepted 7 August 2016

Copyright (C) 2016 International Scholarly Research Notices. This is an open access article distributed under the Creative Commons Attribution License, which permits unrestricted use, distribution, and reproduction in any medium, provided the original work is properly cited.

International Scholarly Research Notices has retracted the article titled "Growth Responses and Leaf Antioxidant Metabolism of Grass Pea (Lathyrus sativus L.) Genotypes under Salinity Stress" [1]. The article was found to contain images with signs of duplication and manipulation in Figures 5(a), 5(b), 6(a), and 6(b), and duplication from Talukdar D. Plant Growth and Leaf Antioxidant Metabolism of Four Elite Grass Pea (Lathyrus sativus) Genotypes, Differing in Arsenic Tolerance. Agric Res (2013) 2: 330. doi:10.1007/s40003-0130085-3 in Figure 6.

\section{References}

[1] D. Talukdar, "Growth responses and leaf antioxidant metabolism of grass pea (Lathyrus sativus L.) genotypes under salinity stress," ISRN Agronomy, vol. 2013, Article ID 284830, 15 pages, 2013. 